\title{
Digitalization in Buildings and Smart Cities on the Way to 6G
}

\author{
Walter Konhäuser ${ }^{1}$
}

Accepted: 28 August 2021 / Published online: 8 September 2021

(C) The Author(s) 2021

\begin{abstract}
The energy turnaround created a high volatility in the energy production based on renewable energy. To integrate renewable energy economically in buildings and smart cities an additional concept of energy storage and energy supply based on energy management concepts must be claimed. The political views have changed during the last years and energy efficiency in buildings is seen important because $35 \%$ of greenhouse gas is produced by the final energy consumption. The deployment of local energy production concepts is an important step to energy turnaround. To generate and distribute energy effectively in buildings, digital components such as sensors, actuators, meters, and energy management systems must be installed in the buildings and the digital components must be able to communicate via communication networks. The paper describes systems for local energy generation, necessary communication networks for buildings and smart cities and digitization applications in industrial buildings. As an example of energy management, the Oktett64 system is presented, which is based on Enterprise IT technology and has implemented AI and blockchain technology. Digitalization with platforms such as Oktett64 are based on technologies that are superior to today's often commercially available Programmable Logic Controllers. The article also shows how the future mobile communications standards $5 \mathrm{G}$ beyond and $6 \mathrm{G}$ can offer special solutions for the digitization of buildings in their edge clouds.
\end{abstract}

Keywords $5 \mathrm{G}$ beyond $\cdot 6 \mathrm{G} \cdot$ Renewable energy $\cdot$ Energy management $\cdot$ IoT $\cdot$ Real estate industry $\cdot$ Industry $4.0 \cdot$ Smart cities $\cdot$ Edge cloud

$\begin{array}{ll}\text { Abbreviations } \\ \text { AI } & \text { Artificial intelligence } \\ \text { CHP } & \text { Combined heat and power unit } \\ \text { DMZ } & \text { Demilitarized zone } \\ \text { DSO } & \text { Distributed service operator } \\ \text { EV } & \text { Electrical vehicle } \\ \text { EV } & \text { Electrical vehicle } \\ \text { FTTH } & \text { Fibre to the home } \\ \text { FPS } & \text { Frames per second }\end{array}$

Walter Konhäuser

walter.konhaeuser@oktett64.de

1 Oktett64 GmbH, Berlin, Germany 


$\begin{array}{ll}\text { HVAC } & \text { Heating and air conditioning } \\ \text { IAV } & \text { Industrie-automation vertriebs-GmbH } \\ \text { KNX-RF } & \text { Open standard for RF-links in buildings } \\ \text { LoRa } & \text { Long range radio technology } \\ \text { mMTC } & \text { Massive machine-type communication } \\ \text { PV } & \text { Photovoltaic } \\ \text { SNR } & \text { Signal-to-noise ratio } \\ \text { UAV } & \text { Unmanned aerial vehicle }\end{array}$

\section{Introduction}

The energy transition initiated by the political policy and the increasing impact of renewable energy consumption in real estate require an additional effective concept of local energy production and energy consumption. Balancing energy consumption between energy production and purchase of energy can only be achieved by an efficient, reliable, and cost-effective energy management system. Heat energy for heating and hot water and electrical energy must be used to power the buildings by means of concepts with reduced $\mathrm{CO} 2$ emissions. In addition, many other tasks in a modern property must be able to be solved cost-effectively with the help of digital components. Local data generation in Smart buildings and Smart cities from sensors, actuators and meters use suitable radio technology as e.g., Bluetooth LE, ZigBee, EnOcean, Z-Wave, KNX-RF. Data transmission to Application Servers and Clouds, where the applications could be deployed, should be managed by central transmission in buildings via gateways. Local date generation can be managed by Software platforms with fast links to different IoT radio technologies. Digitalization of real estate is based on decentralized energy generation, energy storage [1] and energy distribution, installation of intelligent building networks and creating real added values with new applications for residents and administrations (Fig. 1).

The status of the energy supply of real estate is shown in Fig. 2. Real estate is supplied with electrical energy from central power plants that run on fossil fuels via transmission

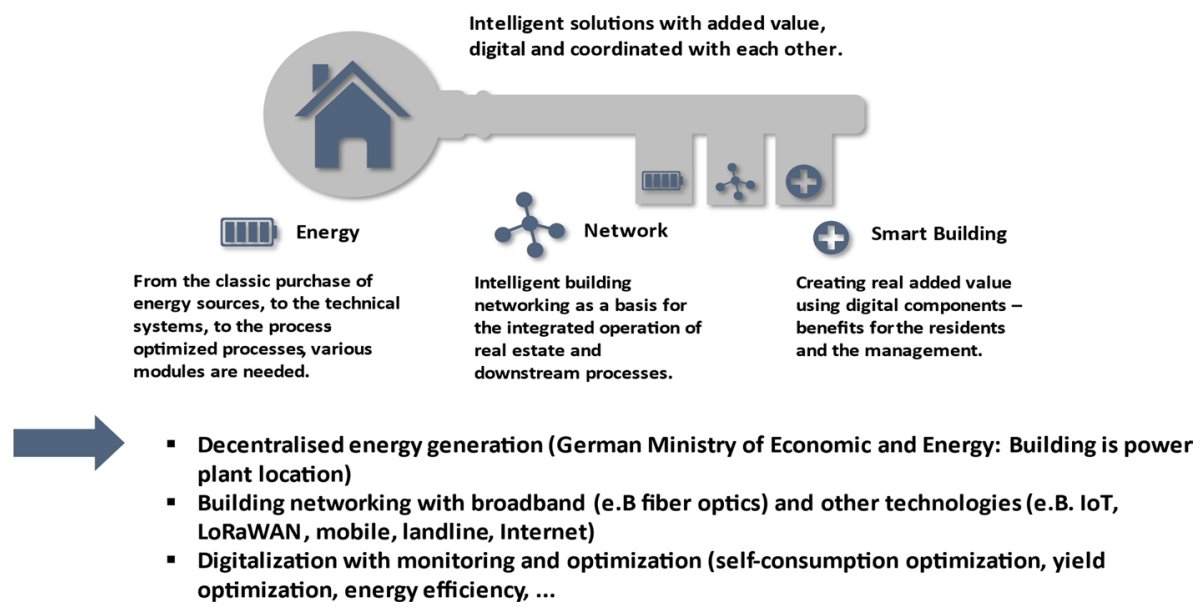

Fig. 1 Basics for digitalization of real estate 


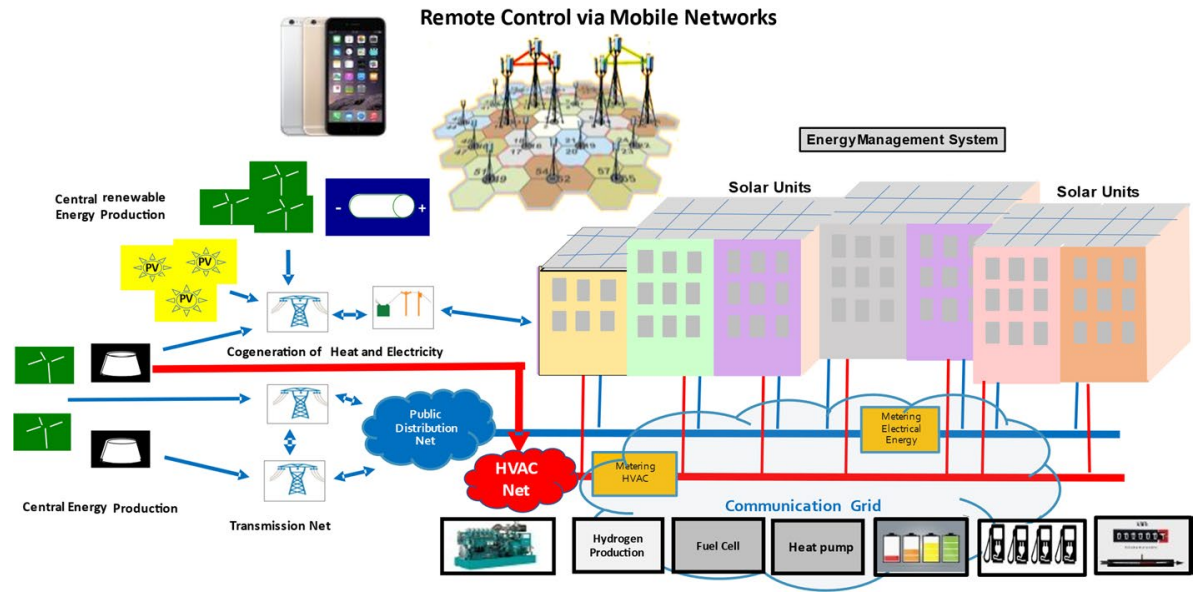

Fig. 2 Today's status of energy supply of real estate and smart cities

grids and distribution grids. At the same time, there are also central wind farms and solar parks for the supply with green energy. Combined heat and power plants can also supply real estate with heat via district heating networks. Today, decentralized energy supply is mostly based on solar units on the roofs and/or CHPs in the basements. Other important local power generation systems are heat pumps and hydrogen production combined with fuel cells. Electrical storage systems decouple energy production from energy consumption and thus increase self-sufficiency. For the control of the decentralized energy supply in cooperation with central energy supply via the public distribution grid, energy management systems must be used, which must also manage the energy procurement from the public grid and energy feed-in into the public grid. Such an energy management system is described in Sect. 3.

\section{Examples of Digital Services in Buildings and Smart Cities}

Digital solutions for the real estate industry concern energy, from the classic purchase of energy sources, through technical systems, to process-optimized processes to reduce $\mathrm{CO} 2$. Furthermore, intelligent building networking is important as a basis for the integrated operation of immobile and downstream processes, and the use of digital components can create real added value for residents and administration. The following selection of digital services should be integrated in real estate [2]:

- Remote access and control of power generation, power consumption and storage (Solar, CHP, etc.),

- Smart metering (electricity, heating, water, etc.),

- Smart home and smart building control with new operation concepts,

- Light control and sun protection,

- Device control: remote control, scene control, reduction of Standby consumption (auto power-off)

- Maximization of self-consumption, 
- HVAC control including air quality monitoring and prevention,

- Network stabilization using buffers and control of local energy production,

- Integrated metering system: deliver data for billing, rent of equipment and extra costs,

- Smoke, fire, water hazard monitoring,

- Access control and security,

- Mobility hub of a quarter: deliver billing data,

- Coordination mobility hub: calculate and regulate charging power for coordination of available network power, generation capacity and user demand,

- Monitoring of technical equipment in buildings (e.g., CHP, DC/AC converter, ...) and

- Media control (FTTH, TV, Internet, phone): deliver billing data (if available from the operator).

Sensors, actuators, meters, communication technology and distributed real-time computing platforms will be key technologies to monitor, control and meter the various electric equipment. This captured information will be used as input for many types of model predictive algorithms (e.g., AI) whose output supports decisions to achieve the goals of the future. For an appropriate control structure, it is essential to stabilize a grid with an architecture based on an appropriate combination of central and decentralized control [3].

Energy Management Systems based on Enterprise IT software architecture allows consumers and market players to compose new services like energy management for small units (offices, apartments, production facilities), energy management for whole buildings and facilities, energy management for urban districts and industry parks with data measurement and metering. Digital control for customer products and applications manages own requirements related to energy services and products thereby also using market interfaces and at the same time supporting the quality and security of supply of the grid-based electricity system. Oktett64, developed on Enterprise IT technology and build as a platform offers vendor independent turnkey solutions based on standards and opensource frameworks including security and operation concepts like DMZ, container, virtualization, optimized for excellent performance at high efficiency. Solution components can be implemented without difficulty and in production quality inside many different systems (including easy to distribute low-end hardware like SoC-systems in the performance range of a Raspberry Pi).

\section{Communication, Digitization in Buildings and Control of Energy Systems with OKTETT64}

For the digitization of buildings, it is very important that high-performance communication networks are installed too. In buildings for communication the following technologies should be deployed:

- Different mobile communication standards and IoT networks (Fig. 3) and

- Fixed networks standards (Fig. 3).

The goal is to establish best suitable architecture for a common Communication Platform (IoT, mobile and fixed networks best merge) to offer appropriate applications via edge cloud servers of $5 \mathrm{G}$ beyond or $6 \mathrm{G}$ mobile networks. The sensors, actuators, meters, etc. to be installed for digitalization need a network through which they can communicate with 


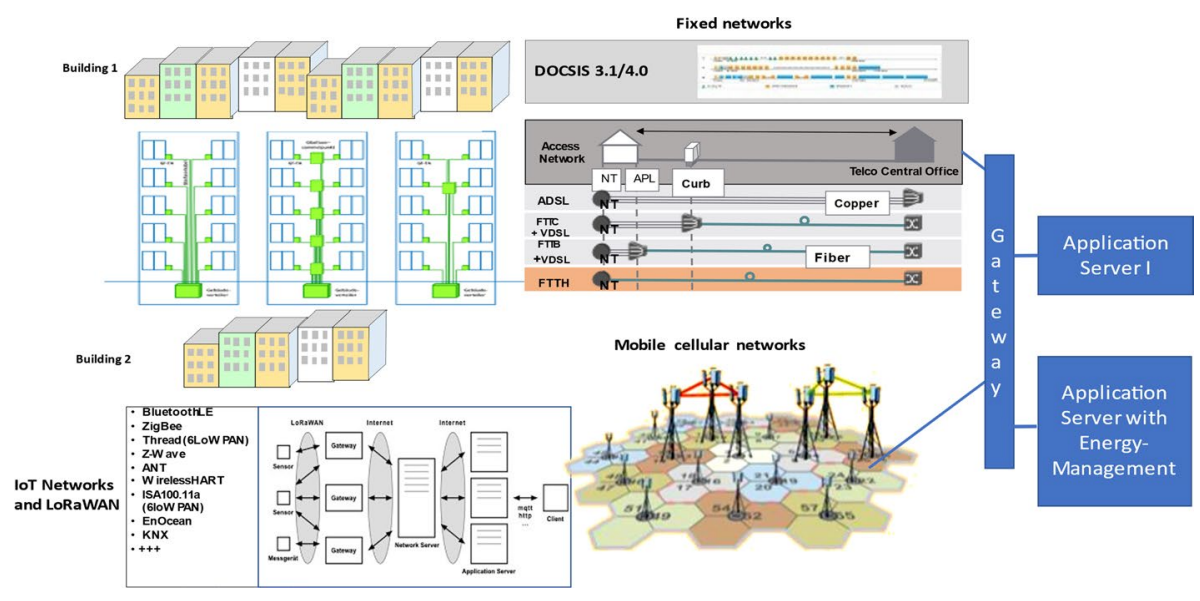

Fig. 3 Mobile, fixed and IoT communication standards for communication in buildings [5]

the energy management system. To store the collected data, internal as well as external cloud systems can be used. IoT systems and LoraWAN connections are an important addition to building communication. The energy management system can also be installed at an external server and is able to control several groups of buildings at the same time. Oktett64 can also take over the gateway function and collect all the data of the sensors and meters and forward them to the external cloud and send the calculated data in the cloud to the actuators. This and other communication networks opportunities are shown in Fig. 3. The Oktett64 platform is built on technologies with open connection of the individual components, no insular solutions, solid architecture based on standards of the enterprise IT. Oktett64 controls operational optimization by influencing consumption and generation performance as well as using direct and indirect storage. Algorithms are used to interfere with a usually continuous control system, controlled by business and demand parameters. The algorithms are dynamically adaptable or self-learning (forecast models). The performance is developed with state-of-the-art software architectures with container and dashboard solutions based on open enterprise IT technologies that have already been tested thousands of times. Oktett64 can be used as cross-vendor turnkey solutions for,

- Energy management in small units, such as offices, apartments, and workshops,

- Energy management in buildings, hotels, or plants,

- Energy management in urban districts or industrial parks,

- Energy management in airport buildings,

- Measurement data acquisition of a wide range of systems, which provide appropriate information on the

- Digital control platform for customer-owned products, applications and for

- Further digitization tasks in real estate.

The Oktett64 architecture and the container structure are shown in Fig. 4. Radio networks, Bus adapters and IoT adapters can be connected via the hardware container. The architecture distinguishes between logical hardware and virtual functions. Connections to other systems, process flow and user interfaces such as dashboards can be established. In the middleware container there are internal databases, if for security reasons no external 


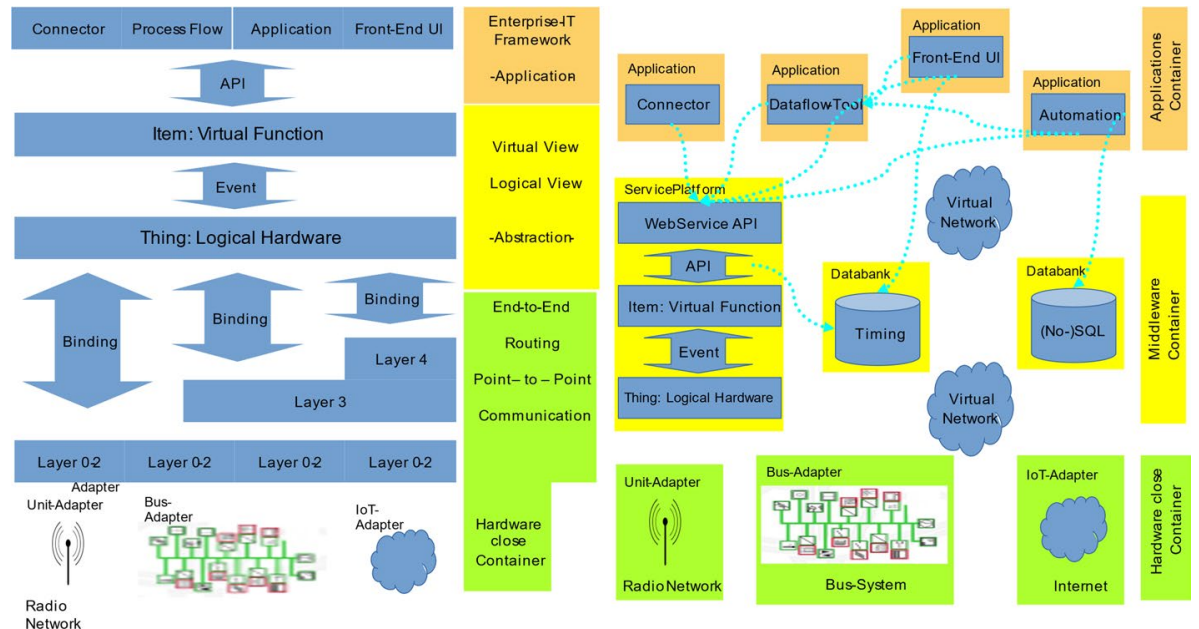

Fig. 4 Oktett64 - architecture from bus to application and architecture in container and associations

cloud solutions should be used to store the data from the sensors and meters. Figure 5 shows the data of a monitoring system in use displayed in a dashboard solution with monitoring of the recorded data. If deviations occur, the system informs the maintenance service.

A holistic solution for an apartment house is shown in Fig. 6. The PV-System on the roof of the building and the CHP in the cellar produce for the Tenants electrical current, warm water-supply and heating-supply. Broadband communication is linked via FTTB

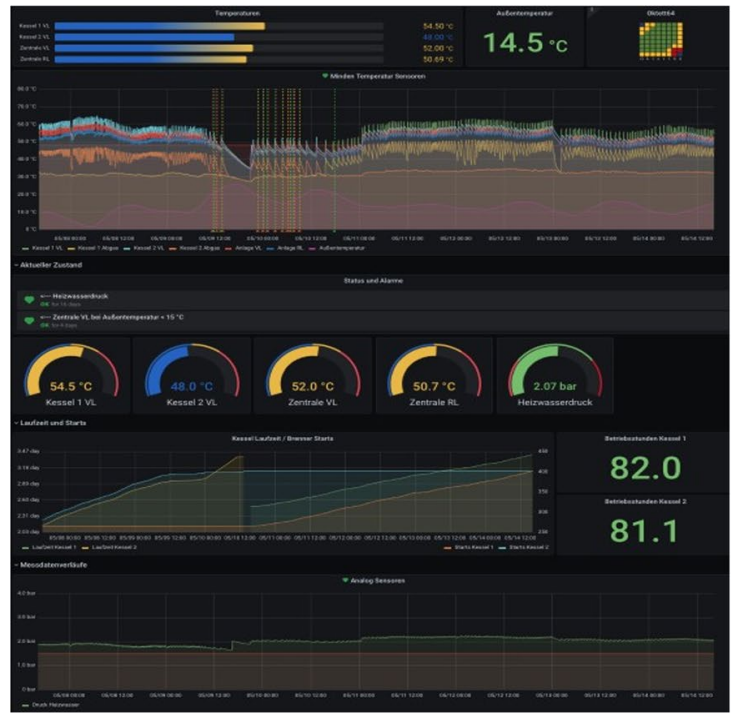

Dashboard with various sensors:

- Temperature heating plant

Forward and return

- Ambient temperature

- Heating water pressure

- Maintenance control button

- .... and much more

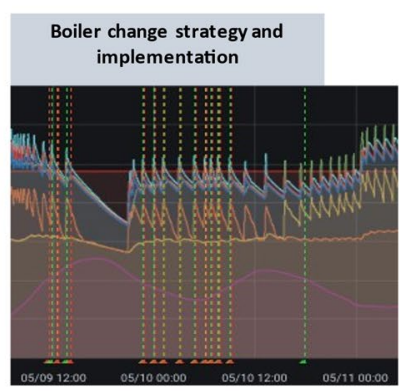

- Review of boiler change timetable and curves

Fig. 5 Oktett64 real time measurement and metering including time-chart analysis 


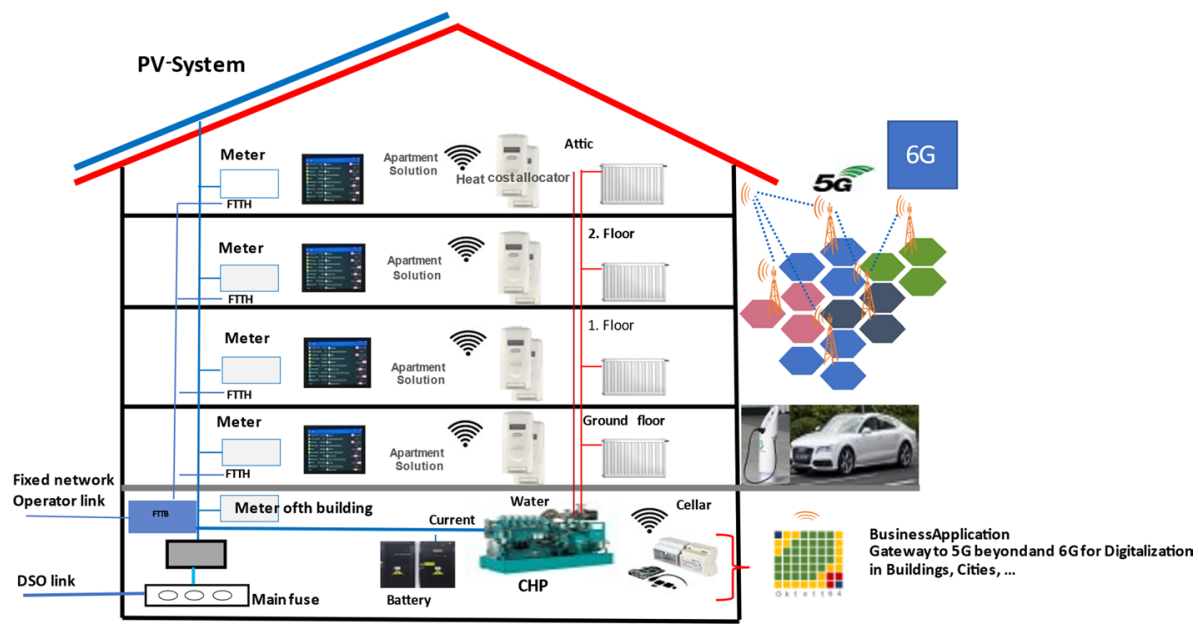

Fig. 6 Holistic solutions: energy supply for tenants with current- and heating-supply in apartment houses, charging systems for EV's, broadband communication supply and gateway to 5G beyond or 6G edge-clouds

access, and the E-Vehicles can be charged with a charging station in front of the building and supplied from the public grid, local energy production or out of the battery. The business application gateway based on Oktett64 platform transmit all information's of the building to the Edge Clouds of $5 \mathrm{G}$ beyond networks or future $6 \mathrm{G}$ networks.

The following requirements by using Application Server and Clouds in the building or at $5 \mathrm{G}$ beyond or $6 \mathrm{G}$ networks for managing Smart buildings and smart cities are requested:

- High network coverage in residential areas,

- High number of subscribers,

- Long-range, low-rate, low-power, low-cost managed services,

- High transfer speed 50Mbit/s (4 K compressed) for entertainment services,

- Fast Handover $(<2 \mathrm{~ms})$,

- Low latency $(<2 \mathrm{~ms})$ for the radio link to transmit entertainment services,

- High data security,

- Deploy of own 5G beyond or 6G private networks (campus network),

- Robust network with less sensitivity contra interference like walls, cellars, halls, high buildings, trees, and weather conditions.

The goal is to establish best suitable architecture for a common Communication Platform (IoT, mobile and fixed networks best merge) to offer appropriate applications via edge cloud server. A smart urban district can be developed to enable interoperability among devices or applications in an urban district environment. Massive IoT data, energy, and equipment monitoring, decentralized efficient energy generation, consumption and distribution are the basis for optimizing the use of different energy resources. Financial energy auditing and grid communication are employed under this framework. The level of complexity of this architecture is increased significantly by considering in the equation demand-side management approaches, different types of renewable energy sources, battery storage systems, electric vehicles, demand response and dynamic pricing. The high density of metering nodes and the amount of data that must be transmitted via low-cost endpoints 
can be easily transported via business application gateway for digitalization in buildings which collects the amount of data from the IoT devices to cloud server in the building or $5 \mathrm{G}$ beyond and $6 \mathrm{G}$ Edge Cloud as use case. Direct links to $5 \mathrm{G}$ networks are possible as well.

At the business application layer deployed in the edge cloud server choice of services can be made. Optimization of operation by steering consumption- and production-power and using direct or implicit storage systems. By means of using algorithms taking place non-linear operations steered by business- and demand-parameters. The algorithms are dynamic tailorable or self-learning (prognosis-model). Remote Maintenance for local energy production $(\mathrm{CHP}, \mathrm{PV}, \ldots)$ and local energy storage, smart metering for energy production and consumption (current, heating and cooling, water, ...) can be managed remote via $5 \mathrm{G}$ beyond or $6 \mathrm{G}$ networks and new operating concept for heating and cooling control, light control, and shutter control just as. Monitoring of different equipment e.g., heating and cooling, light, shutter, indoor climate, air quality, mould avoidance, smoke and fire detection, water detection, admission control and security is basis of a digitalization concept. Further applications are tenant electricity for using the decentralized produced energy and integrated accounted system for generating data for accounting. Connection to balancing power supply from battery system and local energy production can be organized with the DSO and TSO. Mobility hub at urban districts for renting EV's, calculation and control of the electrical power of the charging stations to coordinate power supply of energy production and generating data for accounting should be deployed too (Fig. 7).

\section{Digitalisation and Control of Industry Systems with Oktett64}

For Industry 4.0 applications available 5G beyond and 6G networks can be used just like in the real estate industry. Local data generation and distribution processes in industry areas is realized from sensors with suitable radio technology as e.g., Mesh, LoRa, SigFox and use of existing sensors like field busses as e.g., OPC- UA, Profinet/Profibus, Modbus

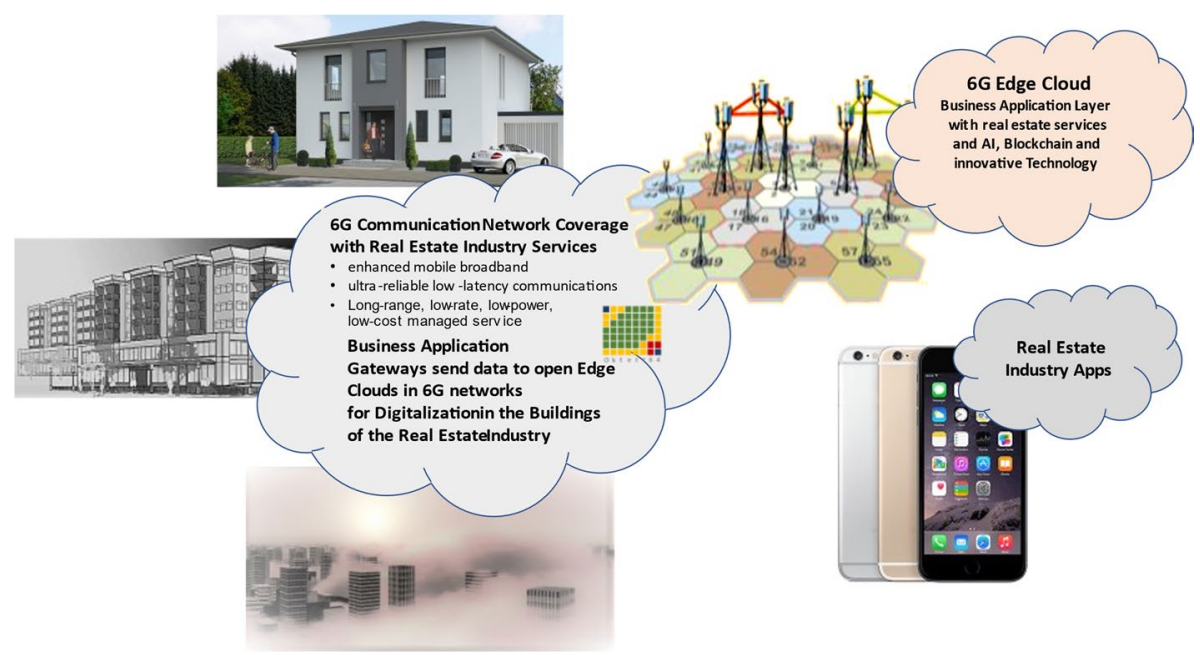

Fig. 7 Mass IoT data collected by gateway and linked to 5G beyond or $6 \mathrm{G}$ edge cloud server 
Ether CAT. Data transmission to $5 \mathrm{G}$ beyond Edge cloud where the applications should be deployed can be managed by central transmission due to costs from much local data via $5 \mathrm{G}$ beyond or $6 \mathrm{G}$ Gateway (e.g., by Oktett64) or optional direct transmission from the machines via $5 \mathrm{G}$ beyond or $6 \mathrm{G}$ radios. Applications are deployed in the Edge Cloud based on AI Technology as (see Fig. 8).

- Visualization of data,

- Condition monitoring,

- Process analysis about the whole production and

- Process automation e.g., minimize downtime, increase efficiency etc.

Applications with Blockchain technology in the Edge Cloud as

- Service data (run time, maintenance) and

- Traceability and reproducibility (e.g., individual production, used machines)

Another innovative business which can be linked to mobile communication systems is controlling drones for different applications. The application scenarios for systemintegrated drones include building monitoring and securing industrial facilities. Wherever security-critical infrastructure is available, drones systems help with monitoring and increases security. For this purpose, a framework has been developed for which, for example, a drone can be connected directly to an alarm system or a computer system [4]. From external signals and information about the weather and the environment, the machine can launch the drone independently and land it precisely again. The mission is therefore carried out without human intervention. Object recognition, AI-based image evaluation, perimeter monitoring and $\mathrm{M} 2 \mathrm{M}$ control together form a strong application and ever with a high sensitivity to aspects of data protection. Data sovereignty is all the time in the hands of the customer. Due to the modular design of the drone, it can be integrated into existing systems. Hardware and software are developed for systemintegrated highly automated drones with M2M interface for many applications. This

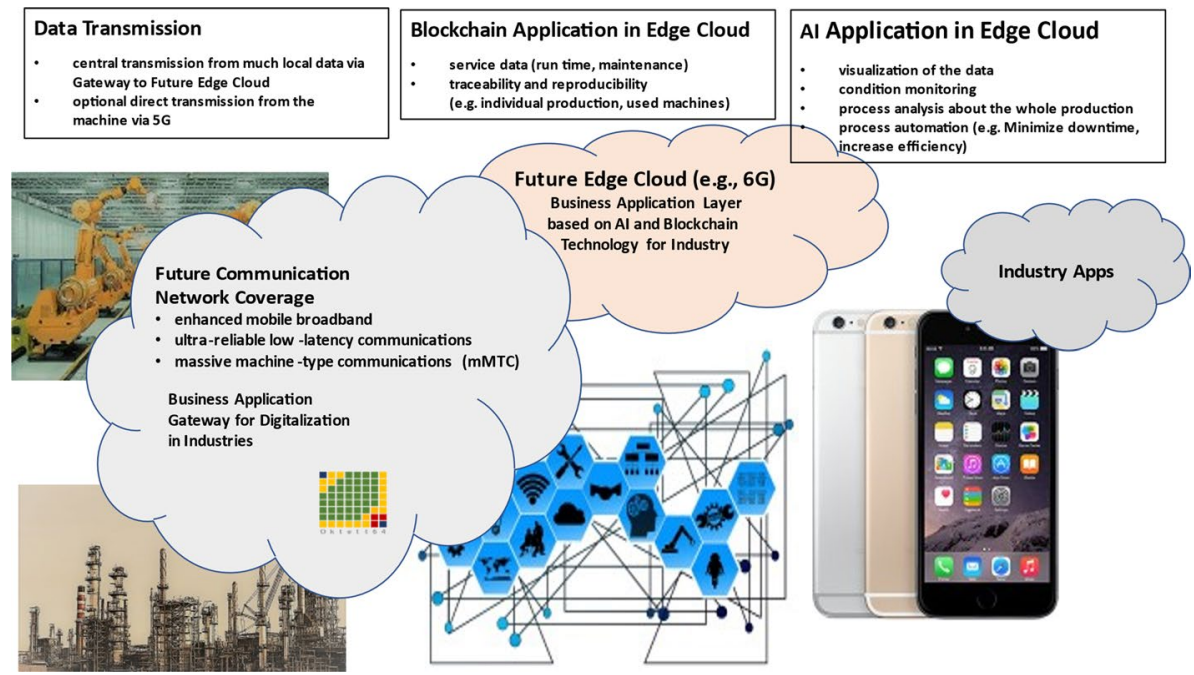

Fig. 8 Industry 4.0 applications 
one-stop solution makes it easier than ever to have vulnerable objects automatically monitored by drones for optimal safety [4]. The requirement views for drone communication [4] are the following:

- Meshed networks with low latency $(<2 \mathrm{~ms})$ for high automated collaborating systems (swarm of different autonomous systems)

- Bandwidth for $4 \mathrm{~K}$ Video transmission, 30 FPS with small or cero compression, ca. 25 Mbit warranted.

- Additional bandwidth for data transmission, ca. 5 Mbit warranted à sum 30 Mbit.

- 5-10 Mbit TCP (Warranty for lossless packet data transmission, reserved for meter-/control data) data lost is unacceptable.

- 10-20 Mbit UDP (packet loss possible and acceptable for video transmission)

- High coverage

- Bandwidth must be warranted independent of distance to the antenna.

- Less interference due to bandwidth, latency through tress and high buildings.

A bird's-eye view often provides the best overall perspective, and some places can only be reached from the air anyway. Therefore, drones are currently undergoing a boom-not only for shooting films but also as flying measurement systems with various sensors. IAV uses well-tried approaches and tools from automotive engineering to open new scenarios for using remote-controlled aerial vehicles. IAV experts are focusing on controlling the UAVs by Wi-Fi, LTE, $5 \mathrm{G}$ and in future $5 \mathrm{G}$ beyond and $6 \mathrm{G}$ on evaluating sensor data and on safety while they are in flight. The INCA-FLOW software defines the task sequence, and a server relays the commands to the drones. Developed in-house, the IAV Mara tool is used for evaluating, organizing, and analysing the data. This combination of readily available drone hardware and proven IAV tools gives you a system that is easy to use for a wide range of different activities. Here are some of the example applications:

- Inspection windmills and solar panels,

- Surveillance of parking areas (Fig. 9),

- Analysing the energy efficiency of buildings,

- Testing the performance of antennas,

- Measurement activities in automotive development,

- Supporting search and rescue activities,

- Supporting firemen with thermography analytics,

- Urban planning,

- Cartography,

- Intra-logistics for industry,

- Package delivery,

- Event and film shooting and

- Agriculture.

Drones (also Unmanned Aerial Vehicles, UAVs) equipped with sensors are ideal for acquiring measurement data in the following situations:

- Inaccessible environments

- Dangerous areas 


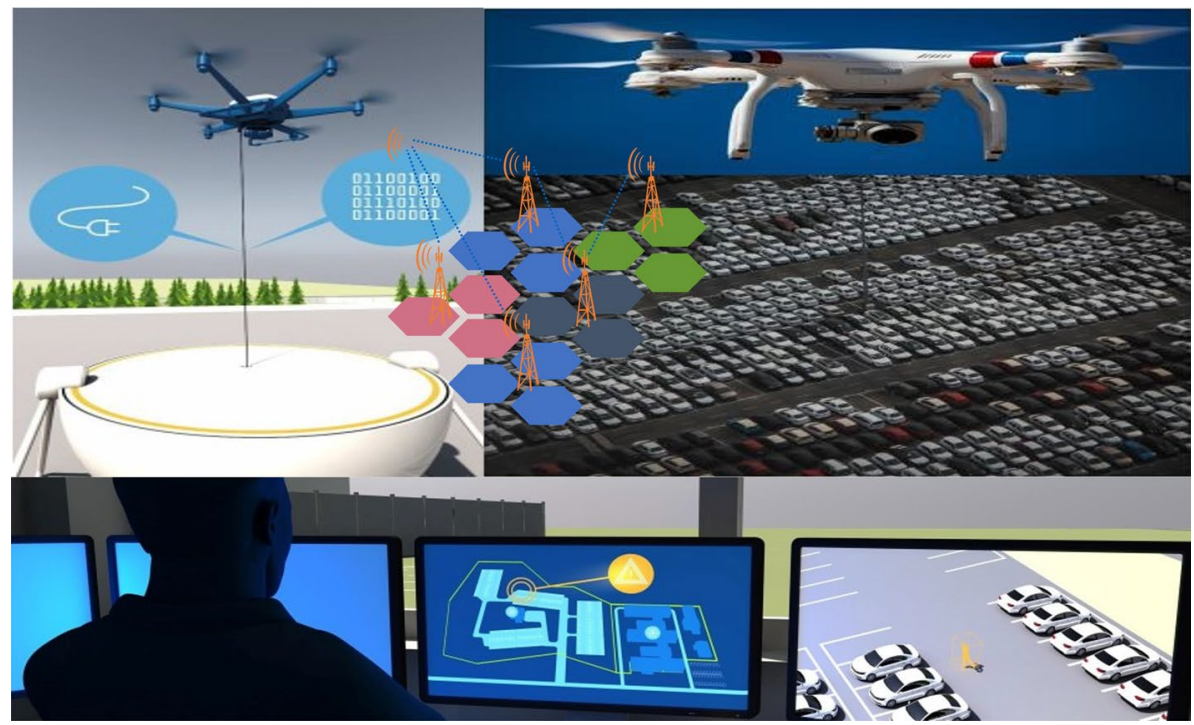

Fig. 9 Drones application: surveillance of parking areas [4]

Besides the actual process of acquiring data, the ability to organize and process large data volumes is particularly relevant in this context. Therefore, IAV connects the drones to a powerful data platform. Here are some of the analysis capabilities:

- Organization of data,

- Historical data analyses,

- Automatic extraction of metadata from measurements,

- Correlating data from other UAVs,

- Connecting UAV data with other information from the Internet,

- Possibility of using artificial intelligence,

- Automatic reporting.

The architecture of the solution [4] consists of different layers with standardized interfaces:

- The UAVs are securely connected to remote control desk through a VPN tunnel in an LTE, 5G, 5G beyond or a Wi-Fi context.

- Flight tasks can easily be customized through the INCA-FLOW method library.

- The drones are equipped with an onboard computer for pre-processing or filtering sensor data (e.g., video data).

- The "Copter Viewer" displays live sensor information during the flight.

- The measurements are stored in a standard format.

- Server-based big data analytics are performed with IAV Mara.

- The block sets of IAV Mara make it extremely easy to customize analytics.

- IAV Mara output is compatible with other standard automotive tools (e.g., MATLAB, Excel, UniPlot or MDA). 


\section{Some More Proposed Requirements on the Way to 6G}

For enabling new business opportunities with innovative services and new business models the following requirements are desirable:

- Core infrastructure sharing,

- Infrastructure crowdsourcing,

- Enhanced spectrum sharing,

- Guaranteed SLA management,

- Enhanced mobile digitalization of industry 4.0

- Vehicle to anything communication,

- Mobile digitalization in real estates,

- Private managed services,

- Deploy of own private networks (campus network),

- Enable B2C, B2B and B2B2X,

- Enhanced tenant electricity concepts (produce, consume, sell),

- Operate as virtual network operator,

- Enhanced business models for contracting, operating, metering,

- Cost efficient services.

- ...

To improve operations and management the following tasks should be implemented:

- Real-time operation

- Enhanced mobile broadband

- Improved network scalability

- Operational safety

- Massive machine-type communication (mMTC)

- Ultra-reliable low-latency communication

- Long-range, low-rate, low-power, low-cost managed service

- Artificial intelligence (AI)

- Blockchain technology

- ..

\section{Conclusions}

The 5G standard is taking part to improve everyday life and economy. The success of a new generation of mobile communication systems is mainly based on new technologies which enables new applications to address new market potentials. 5G and future 5G beyond on the way to $6 \mathrm{G}$ is expected to address with new services industry, energy, mobility, real estate industry, etc. and will generate a high number of applications. The paper describes a communication platform to generate new applications for real estate industry, industry 4.0 applications and new drone applications, which will become important in the future, based on possible business association with future mobile networks. The new technologies should be used for creating Green Deals too. With 5G beyond and future 6G a lot of new applications and business opportunities are available for creating Green Deals and reduce 
$\mathrm{CO} 2$ emissions. With 5G beyond and 6G a lot of new applications and business opportunities are envisaged, and future applications deployed in the Edge Clouds of mobile networks would extend business opportunities and finally a holistic communication concept based on $6 \mathrm{G}$ would be challenging. The buildings and especially the existing buildings still generate a lot of $\mathrm{CO} 2 \mathrm{~s}$ today. A special help for the digitization of the buildings and thus local green energy generation would be special services for the properties from the mobile networks, offered by the mobile operators. Future $5 \mathrm{G}$ beyond and $6 \mathrm{G}$ networks should be geared towards this. Time is of the essence!

Funding Open Access funding enabled and organized by Projekt DEAL.

Open Access This article is licensed under a Creative Commons Attribution 4.0 International License, which permits use, sharing, adaptation, distribution and reproduction in any medium or format, as long as you give appropriate credit to the original author(s) and the source, provide a link to the Creative Commons licence, and indicate if changes were made. The images or other third party material in this article are included in the article's Creative Commons licence, unless indicated otherwise in a credit line to the material. If material is not included in the article's Creative Commons licence and your intended use is not permitted by statutory regulation or exceeds the permitted use, you will need to obtain permission directly from the copyright holder. To view a copy of this licence, visit http://creativecommons.org/licenses/by/4.0/.

\section{References}

1. Konhäuser, W. The next mobile communication steps into new application areas; $5 \mathrm{~g}$ outlook-innovations and applications. River Publishers. ISBN 978-87-93379-77-0.

2. Kastner, T., Konhäuser, W., \& Schuck, I. Energieeffizienz dank effizienter Prozesse; Die Wohnungswirtschaft, Ausgabe 05/2021.

3. Decentralized transactive energy; white paper WEC (World Energy Consortium).

4. IAV; support from the air; remote controlled drones as flying measurement systems.

5. Deutsche Telekom: Glasfaser-Inhouse-Verlegung.

Publisher's Note Springer Nature remains neutral with regard to jurisdictional claims in published maps and institutional affiliations.

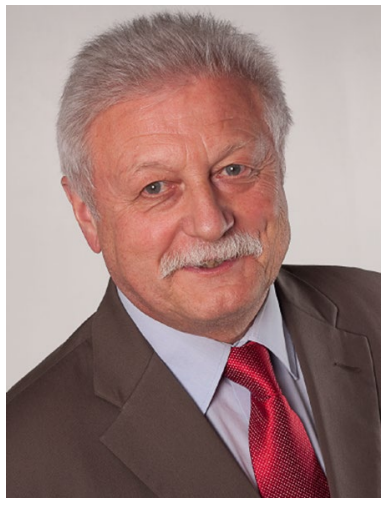

Prof. Dr.-Ing. habil. Walter Konhäuser was born in Ruhpolding, South Germany.He studied electrical engineering at the Technical University in Berlin and finalized with PhD. In 2007 he was appointed to Professor for Mobile Communication Systems at Technical University Berlin. Since joining Siemens in 1982 he has been involved in a variety of assignments. For eighteen years he has worked in the mobile networks business and was CTO within the mobile infrastructure business of Siemens. In 2004 he became President for the WLAN business with worldwide business responsibility. Since 2010 he works as independent professional as Executive Consultant with ITCcon GmbH, Potsdam and as Senior Consultant at Xiopia GmbH, Unterföhring. In 2013 he became Partner at Hoseit-Unternehmensberatung and 2017 associate Partner at Management Consultant Kastner GmbH \& Co.KG. Since 2019 he is co-founder and General Manager of Oktett64 GmbH. The company is working on a decentralized energy management concept for digitalization in different industries based on vendor independent turnkey solutions, on standards and Open Source frameworks including security and operation concepts. Prof. Dr. Konhäuser was PCC chairman of the European ACTS FRAMES Project and Board Member of the Wireless World Research Forum (WWRF). He is a member of 
the VDE, the German Association of Electrical Engineers and is Spokesman of the regional VDE organization in Berlin and Brandenburg. 